\title{
Changes of serum retinol-binding protein 4 associated with improved insulin resistance after laparoscopic sleeve gastrectomy in Chinese obese patients
}

Xingchun Wang ${ }^{1,2 \dagger}$, Yueye Huang ${ }^{1,2 \dagger}$, Jingyang Gao ${ }^{1,2}$, Hang Sun ${ }^{1,2}$, Muthukumaran Jayachandran ${ }^{1,2}$ and Shen $\mathrm{Qu}^{1,2^{*}}$

\begin{abstract}
Background: Serum retinol-binding protein 4 (RBP4) plays a critical role in insulin resistance. The mechanism behind the impact of laparoscopic sleeve gastrectomy (LSG) on glucose metabolism is unclear. Hence, we aimed to investigate the triangle relationship between the RBP4, glucose metabolism, and LSG in patients of Chinese ethnicity.

Methods: The study enrolled eighty-two obese patients. Glucose-lipid metabolic index, uric acid (UA), superoxide dismutase (SOD), free triiodothyronine (FT3), free thyroxin (FT4) and thyrotropin (TSH) were measured. RBP4 levels were detected by enzyme-link immunosorbent assay. 30 obese patients underwent LSG were studied. All these markers were measured again at a time interval of 3 and 6 months after surgery.

Results: (1) Circulating RBP4 levels were positively associated with body mass index(BMI), blood glucose in 0 min (BG0), BG30, BG120, BG180, fasting inulin(FINS), fasting C peptide(FCP), homeostasis model of assessment for insulin resistance index (HOMA-IR), SOD, TSH and negatively associated with Matsuda index in obesity with a significant difference $(P<0.05)$. RBP4 levels in the patients with impaired fasting glucose $(I F G)$, insulin resistance or hyperinsulinemia were significantly higher than the patients without IFG, insulin resistance or hyperinsulinemia $(P=0.035, P=0.001$, and $P=0.007$ ). (2) LSG resulted in significantly decreased FBG, FINS, FCP and HOMA-IR at 3, 6 months after surgery (all $P<0.05$ ). The RBP4 levels were significantly decreased after surgery (all $P<0.05$ ) with no gender difference. (3) The change in RBP4 levels was significantly associated with the change in FINS, FCP, HOMA-IR, and HOMA- $\beta$ at 6 months and the change in TSH at 3 months after surgery in males (all $P<0.05$ ). The change in RBP4 levels were significantly associated with the change in FINS, FCP, HOMA-IR, HOMA- $\beta$, and TCH at 3 months after surgery in females (all $P<0.05$ ).

Conclusions: Overall, our results interpret the significant correlations between RBP4, glucose-lipid metabolism, oxidative stress and thyroid function in obese patients. Further, the LSG brings a decline in RBP4 levels and that may contribute partly to the improved insulin resistance in obese Chinese patients.
\end{abstract}

Keywords: Retinol binding protein 4, Insulin resistance, Laparoscopic sleeve gastrectomy, Obesity

*Correspondence: qushencn@hotmail.com

${ }^{\dagger}$ Xingchun Wang and Yueye Huang contributed equally to this work

${ }^{1}$ Department of Endocrinology and Metabolism, Shanghai Tenth People's Hospital, Tongji University, School of Medicine, Shanghai, China

Full list of author information is available at the end of the article

\section{Background}

Lifestyle changes contribute significantly to the increased prevalence of obesity worldwide. Obesity causes type 2 diabetes and associated chronic complications [1-3]. Therefore the prevention and treatment of obesity should be given much importance. Lifestyle modifications such

c) The Author(s) 2020. This article is licensed under a Creative Commons Attribution 4.0 International License, which permits use, sharing, adaptation, distribution and reproduction in any medium or format, as long as you give appropriate credit to the original author(s) and the source, provide a link to the Creative Commons licence, and indicate if changes were made. The images or other third party material in this article are included in the article's Creative Commons licence, unless indicated otherwise in a credit line to the material. If material is not included in the article's Creative Commons licence and your intended use is not permitted by statutory regulation or exceeds the permitted use, you will need to obtain permission directly from the copyright holder. To view a copy of this licence, visit http://creativeco mmons.org/licenses/by/4.0/. The Creative Commons Public Domain Dedication waiver (http://creativecommons.org/publicdomain/ zero/1.0/) applies to the data made available in this article, unless otherwise stated in a credit line to the data. 
as dietary intervention and physical activity are regarded as first-line therapy. However, its efficacy is limited in severe or morbid obesity. The usage of weight-loss drugs are limited due to their side effects. Therefore, bariatric surgery will be a better treatment option for morbidly obese subjects or obesity with comorbidities. Previous studies have proven that bariatric surgery is effective in reducing body weight and improving glucose-lipid metabolism in obese patients [4-7].

Retinol-binding protein 4 (RBP4) is mainly released by the human liver and adipose tissue [8]. RBP4 is not just a plasma carrier of retinol but also considered as a novel adipokine that plays an important role in insulin resistance [9]. It is indicated that RBP4 concentrations are elevated in insulin-resistant mice and humans with obesity and diabetes and can be normalized by insulinsensitizing drugs [10]. Additionally, RBP4 has a function in the fat deposition by impairing the insulin pathway in mice [11]. A study on 1033 Chinese subjects with various degrees of obesity has shown that Serum RBP4 levels were positively correlated with visceral adipose tissue $(P<0.001)$ [12]. Several other studies exhibit the interrelation between RBP4, inflammation markers and oxidative stress $[8,13]$.

RBP4 levels were decreased after weight loss, including bariatric surgery [14]. With context to this, a previous study showed that serum RBP4 levels are reduced after gastric banding surgery in 33 morbidly obese patients with body mass index (BMI) of $46 \pm 5 \mathrm{~kg} / \mathrm{m}^{2}$ [14], and the decreased RBP4 may contribute to improved insulin resistance after banding surgery with weight loss [14]. Also, a study found that the RBP4 levels start to decrease within 6 months after surgical bypass in 190 morbid obesity [15]. After banding or bypass surgery, RBP4 is decreased by about $16.6 \%$ [16], and the change in RBP4 levels are related to reductions of waist circumference (WC), waist-hip ratio (WHR) and visceral-fat diameter (all $P<0.0 .5$ ) [16].

To the extent of our knowledge, there is no report about the change in RBP4 levels after laparoscopic sleeve gastrectomy (LSG) in obese patients of Chinese ethnicity. We hypothesis that change in RBP4 may associate with the improvement of glucose metabolism after LSG. Hence, this study was designed to investigate the association between RBP4 and glucose-lipid metabolic markers in patients of Chinese ethnicity and change in RPB4 levels after LSG.

\section{Materials and methods Subjects}

An observational study of 34 men and 48 women subjects with obesity were enrolled from the Endocrine and Metabolism Department of Shanghai Tenth People's
Hospital. The obesity was defined by BMI over $30 \mathrm{~kg} /$ $\mathrm{m}^{2} .10$ healthy persons with normal BMI (average BMI $20.22 \pm 1.15 \mathrm{~kg} / \mathrm{m}^{2}$ ) were included as controls. Among obese patients, 30 subjects (males:female $=10: 20$ ) underwent LSG. Inclusion criteria: BMI ranged from 31.16 to $52 \mathrm{~kg} / \mathrm{m}^{2}$ and age ranged from 18 to 60 years old which meets the recommended cutoff for bariatric surgery in Asians. Exclusion criteria: (1) secondary cause of obesity: hypothalamic obesity, Cushing syndrome, and hypophysis dysfunction, etc., (2) pregnancy or lactation, (3) taking antipsychotic medication, (4) presence of severe complications of obesity and diabetes, (5) Gastrointestinal diseases that contraindications for laparoscopic surgery, such as intra-abdominal infection, adhesions, etc., (6) Severe organic and systemic diseases intolerant of surgery (e.g. malignant tumor, severe heart, liver and kidney dysfunction, mental illness, autoimmune disease, acute or chronic inflammation, etc.). These subjects were examined before the LSG and followed up at 3, 6 months after surgery. For all patients in this cohort, this was the primary bariatric procedure and none have required an additional bariatric operation. The operation was performed by a professional surgeon under standard procedures, and under general anesthesia induced with a tracheal cannula. After $\mathrm{CO}_{2}$ pneumoperitoneum was established, a laparoscope was used to explore the abdominal cavity. Four other trocars were inserted through incisions alongside the bilateral rectus abdominis muscles, the right side of the midline, and below the costal margin. A LigaSure Atlas (Covidien, Inc.) was used to take down the inner side of the hemal arch from the greater curvature to the fundus of the stomach entirely. A stent was planted in the lesser curvature, and an Echelon (Ethicon Endo-Surgery, Inc.) was used to cut and close the stomach from the pylorus ring to the fundus of the stomach several times to make the stomach like a tube. A Stratafix (Ethicon Endo-Surgery, Inc.) was used to make a continuous suture in the greater curvature of the stomach. Then, the incision was checked to avoid bleeding, and part of the stomach from navel incision was taken out. Negative pressure drainage was applied in the splenic recess and led to the right incision. Informed consent was signed and obtained by all individual participants included in this study. This study was approved by the Shanghai Tenth People's ethical committee.

\section{Anthropometric measurements}

Anthropometric data including body weight and height were measured without shoes and with light clothing by professional staff. We calculated the BMI by weight in kilograms divided by height in meters squared. WC and hip circumference $(\mathrm{HC})$ were also measured. WC 
was measured at the midway between the lower rib margin and the iliac crest. HC was measured at the top point around the buttocks. The WHR was calculated as $\mathrm{HC}$ divided by WC.

\section{Laboratory tests}

Venous blood samples were adopted from all the subjects at least fasting for $8 \mathrm{~h}$ at baseline and 3, 6 months after LSG in the subjects under LSG. The serum was centrifuged immediately and stored at $-80{ }^{\circ} \mathrm{C}$. Lipid metabolic markers [total cholesterol $(\mathrm{TCH})$, triglyceride (TG), high density lipoprotein cholesterol (HDL-C), low density lipoprotein cholesterol (LDL-C), free fatty acid (FFA)], uric acid (UA) and superoxide dismutase (SOD) were measured by Roche Cobas c701 fully automatic biochemical analyzer. Free triiodothyronine (FT3), free thyroxin (FT4) and thyroid-stimulating hormone (TSH) were measured by ADVIA Centaur XP Immunoassay System. A 75 g-oral glucose tolerance test (OGTT) was performed to estimate glucose metabolism and insulin clearance according to the methods demonstrated by World Health Organization [17]. The glucose, insulin and C-peptide levels at 0, 30, 60, 120 and 180 min were measured. Glucose was measured by by Roche Cobas c701 fully automatic biochemical analyzer, insulin and C-peptide were measured by Roche Cobas e 601 analyzer.

The HOMA of insulin resistance (HOMA-IR) was calculated to assess insulin resistance by the following formula: fasting serum insulin concentration $(\mathrm{uIU} / \mathrm{mL}) \times$ fasting blood glucose concentration (mmol/L)/22.5 [18]. HOMA$\beta$ was calculated to evaluate beta-cell function: HOMA$\beta=20 \times$ fasting insulin/(fasting glucose -3.5 ) [18]. Insulin sensitivity was evaluated by the Matsuda index. Matsuda index was calculated as the following formula: Matsuda $=1000 / \sqrt{\text { Glu } 0 \times \text { INS0 } \times \text { MeanGlu } \times \text { MeanIns }}$

Serum retinol-binding protein 4 was detected by enzymelink immunosorbent assay (R\&D Systems, Catalog Number DRB400).

\section{Definition of glucose-lipid metabolic disorders}

Impaired fasting glucose (IFG) was defined by fasting glucose levels $\geq 5.6 \mathrm{mmol} / \mathrm{L}$ [20]. Hyperinsulinemia and insulin resistance (IR) were defined by FINS concentrations $\geq 15 \mathrm{mU} / \mathrm{L}$ and HOMA-IR $\geq 2.5$ respectively [21]. Hypertriglyceridemia, hypercholesterolemia, low HDL-C, and high LDL-C were defined by fasting plasma $\mathrm{TG} \geq 1.7 \mathrm{mmol} / \mathrm{L}, \mathrm{TCH} \geq 5.18 \mathrm{mmol} / \mathrm{L}$, $\mathrm{LDL}-\mathrm{C} \geq 3.37 \mathrm{mmol} / \mathrm{L}$ and $\mathrm{HDL}-\mathrm{C}<1.04 \mathrm{mmol} / \mathrm{L}$ respectively.

\section{Statistical analysis}

SPSS20.0 statistical software was used to analyze the data. Descriptive statistics were expressed as mean \pm standard deviation $(\mathrm{X} \pm \mathrm{SD})$. Count data were expressed as number (n). An independent sample-test was used to compare the data between two independent groups. Statistical significance before and after surgery was evaluated using the paired two-tailed t-test. Nonparametric tests were used for non-normal distributed data. Pearson's and Spearman's correlation coefficient was used for correlations between RBP4 levels and other markers. The difference was considered significant at a $P$ value of less than 0.05 .

\section{Results}

Baseline characteristics

There were a total of 82 obese patients enrolled (males:females $=34: 48$ ) with average BMI $35.20 \pm 6.69 \mathrm{~kg} / \mathrm{m}^{2} . \quad 10$ healthy persons aged $32.08 \pm 9.84$ years old (males:females $=4: 6$ ) with average BMI $20.22 \pm 1.15 \mathrm{~kg} / \mathrm{m}^{2}$ were enrolled as a control group. RBP4 levels were significantly higher in obese patients than healthy weight controls $(53.53 \pm 17.12 \mathrm{mg} / \mathrm{L}$ vs. $37.39 \pm 11.70 \mathrm{mg} / \mathrm{L}, P<0.001)$ as presented in Fig. $1 . \mathrm{RBP} 4$ levels between genders show no significant difference in obese patients $(54.59 \pm 18.66$ vs. $51.23 \pm 15.94 \mathrm{mg} / \mathrm{L}$, $P=0.416$ ). Additionally, the average BMI of 30 obese subjects (males:female $=10: 20$ ) who underwent LSG was $38.97 \pm 4.83 \mathrm{~kg} / \mathrm{m}^{2}$ and the average age of them was $33.16 \pm 11.03$ years old. Markers of glucose-lipid metabolism of the 30 obesity subjects were presented in Table 2.

\section{Correlations of serum RBP4 levels with other parameters}

RBP4 levels were significantly and positively associated with BMI, BG0, BG30, BG120, BG180, INS0, CP0, HOMA-IR, SOD, TSH and negatively associated with Matsuda index in all obesity (all $P<0.05)$. RBP4 levels were significantly and positively associated with UA, BG0, BG30, BG120, BG180, INS0, CP0, HOMA-IR, HGB,

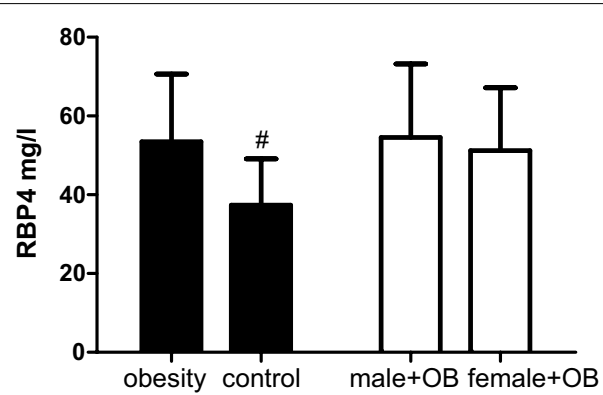

Fig. 1 RBP4 levels among groups. RBP4 retinol-binding protein 4, OB obesity; compared to obesity, ${ }^{\#} P<0.001$ 
SOD, TCH and TG in females with obesity (all $P<0.05$ ). RBP4 levels were only significantly and positively associated with HOMA-IR, SOD and negatively with the Matsuda index in males with obesity (all $P<0.05$ ). All the results were showed in Table 1. Among the obese subjects, $41.1 \%$ had IFG, $77.7 \%$ had insulin resistance and $68.6 \%$ had hyperinsulinemia. RBP4 levels of the patients with IFG, insulin resistance or hyperinsulinemia were significantly higher than the patients without IFG, insulin resistance or hyperinsulinemia $(57.39 \pm 17.34 \mathrm{mg} / \mathrm{L}$ vs. $48.52 \pm 16.29 \mathrm{mg} / \mathrm{L}, P=0.035 ; 55.18 \pm 16.90 \mathrm{mg} / \mathrm{L}$ vs. $39.57 \pm 12.45 \mathrm{mg} / \mathrm{L}, P=0.001 ; 55.58 \pm 17.81 \mathrm{mg} / \mathrm{L}$ vs. $44.33 \pm 13.67 \mathrm{mg} / \mathrm{L}, P=0.007)$. Additionally, RBP4 levels of the patients with hypertriglyceridemia or hypercholesterolemia were significantly higher than patients with normal TG or TCH $(59.36 \pm 16.82 \mathrm{mg} / \mathrm{L}$ vs. $46.92 \pm 14.76 \mathrm{mg} / \mathrm{L}, P=0.029$, and $60.66 \pm 19.74 \mathrm{mg} / \mathrm{L}$ vs $47.36 \pm 13.88 \mathrm{mg} / \mathrm{L}, P=0.028)$. RBP4 levels of the patients with higher LDL-C or lower HDL-C were slighter higher than corresponding control groups $(54.85 \pm 20.04 \mathrm{mg} / \mathrm{L}$ vs. $47.96 \pm 13.36 \mathrm{mg} / \mathrm{L}, P=0.205$ and $49.38 \pm 16.10 \mathrm{mg} / \mathrm{L}$

Table 1 Correlation of RBP4 with metabolic parameters

\begin{tabular}{|c|c|c|c|c|c|c|}
\hline \multirow{2}{*}{$\begin{array}{l}\text { Parameter } \\
\mathrm{N}=82\end{array}$} & \multicolumn{2}{|c|}{ All obesity } & \multicolumn{2}{|l|}{ Males } & \multicolumn{2}{|l|}{ Females } \\
\hline & $r$ & $P$ & $r$ & $P$ & $r$ & $P$ \\
\hline $\mathrm{BMI}$ & 0.376 & 0.001 & 0.207 & 0.281 & 0.208 & 0.216 \\
\hline WC & 0.301 & 0.136 & 0.253 & 0.428 & -0.86 & 0.770 \\
\hline $\mathrm{HC}$ & 0.185 & 0.366 & 0.308 & 0.330 & -0.348 & 0.223 \\
\hline WHR & 0.322 & 0.108 & -0.144 & 0.302 & 0.403 & 0.153 \\
\hline $\mathrm{BG} 0 \mathrm{~min}$ & 0.351 & 0.003 & 0.356 & 0.058 & 0.346 & 0.031 \\
\hline BG30 min & 0.303 & 0.023 & 0.041 & 0.838 & 0.408 & 0.028 \\
\hline $\mathrm{BG} 60 \mathrm{~min}$ & 0.241 & 0.073 & 0.009 & 0.963 & 0.300 & 0.113 \\
\hline $\mathrm{BG} 120 \mathrm{~min}$ & 0.289 & 0.024 & 0.173 & 0.369 & 0.401 & 0.023 \\
\hline BG180 min & 0.295 & 0.027 & 0.248 & 0.212 & 0.378 & 0.043 \\
\hline INSO min & 0.349 & 0.004 & 0.249 & 0.184 & 0.425 & 0.011 \\
\hline INS30 min & 0.078 & 0.565 & 0.201 & 0.316 & -0.214 & 0.265 \\
\hline INS60 min & 0.033 & 0.810 & 0.305 & 0.122 & -0.253 & 0.185 \\
\hline INS120 min & 0.109 & 0.403 & 0.116 & 0.548 & 0.108 & 0.557 \\
\hline INS180 min & 0.260 & 0.053 & 0.244 & 0.220 & 0.273 & 0.152 \\
\hline CPO min & 0.283 & 0.022 & 0.243 & 0.187 & 0.417 & 0.014 \\
\hline CP30 min & 0.030 & 0.826 & 0.071 & 0.724 & -0.108 & 0.583 \\
\hline CP60 min & -0.161 & 0.240 & 0.040 & 0.844 & -0.286 & 0.140 \\
\hline CP120 min & -0.089 & 0.503 & 0.034 & 0.861 & 0.084 & 0.658 \\
\hline CP180 min & 0.195 & 0.153 & 0.119 & 0.554 & 0.267 & 0.169 \\
\hline HOMA-IR & 0.412 & 0.001 & 0.420 & 0.026 & 0.418 & 0.012 \\
\hline HOMA- $\beta$ & -0.117 & 0.362 & 0.124 & 0.530 & 0.063 & 0.721 \\
\hline Matsuda index & -0.399 & 0.003 & -0.480 & 0.015 & -0.307 & 0.106 \\
\hline $\mathrm{HGB}$ & 0.263 & 0.065 & 0.085 & 0.708 & 0.408 & 0.031 \\
\hline $\mathrm{TCH}$ & 0.175 & 0.143 & 0.146 & 0.427 & 0.492 & 0.001 \\
\hline $\mathrm{TG}$ & 0.079 & 0.514 & 0.028 & 0.878 & 0.444 & 0.005 \\
\hline $\mathrm{HDL}-\mathrm{C}$ & -0.017 & 0.889 & 0.068 & 0.710 & 0.111 & 0.500 \\
\hline LDL-C & 0.118 & 0.327 & 0.163 & 0.371 & 0.221 & 0.177 \\
\hline FFA & 0.117 & 0.336 & 0.101 & 0.581 & 0.175 & 0.292 \\
\hline UA & 0.142 & 0.238 & -0.046 & 0.806 & 0.371 & 0.019 \\
\hline SOD & 0.486 & $<0.001$ & 0.603 & 0.001 & 0.381 & 0.041 \\
\hline FT3 & 0.205 & 0.094 & 0.321 & 0.073 & 0.127 & 0.461 \\
\hline FT4 & -0.086 & 0.480 & -0.159 & 0.384 & -0.033 & 0.844 \\
\hline TSH & 0.274 & 0.023 & 0.324 & 0.071 & 0.099 & 0.560 \\
\hline
\end{tabular}

$B M I$ body mass index, WC waist circumference, $H C$ hip circumference, WHR waist to hip ratio, $B G$ blood glucose, INS insulin, $C P C$ peptide, $H O M A-I R$ homeostasis model of assessment for insulin resistance index, $H G B$ glycosylated hemoglobin, $T G$ triglyceride, $T C H$ total cholesterol, $L D L-C$ low density lipoprotein cholesterol, $H D L-C$ high density lipoprotein cholesterol, FFA free fatty acid, UA uric acid, SOD superoxide dismutase, FT3: FT4 free thyroxine, TSH thyroid stimulating hormone 

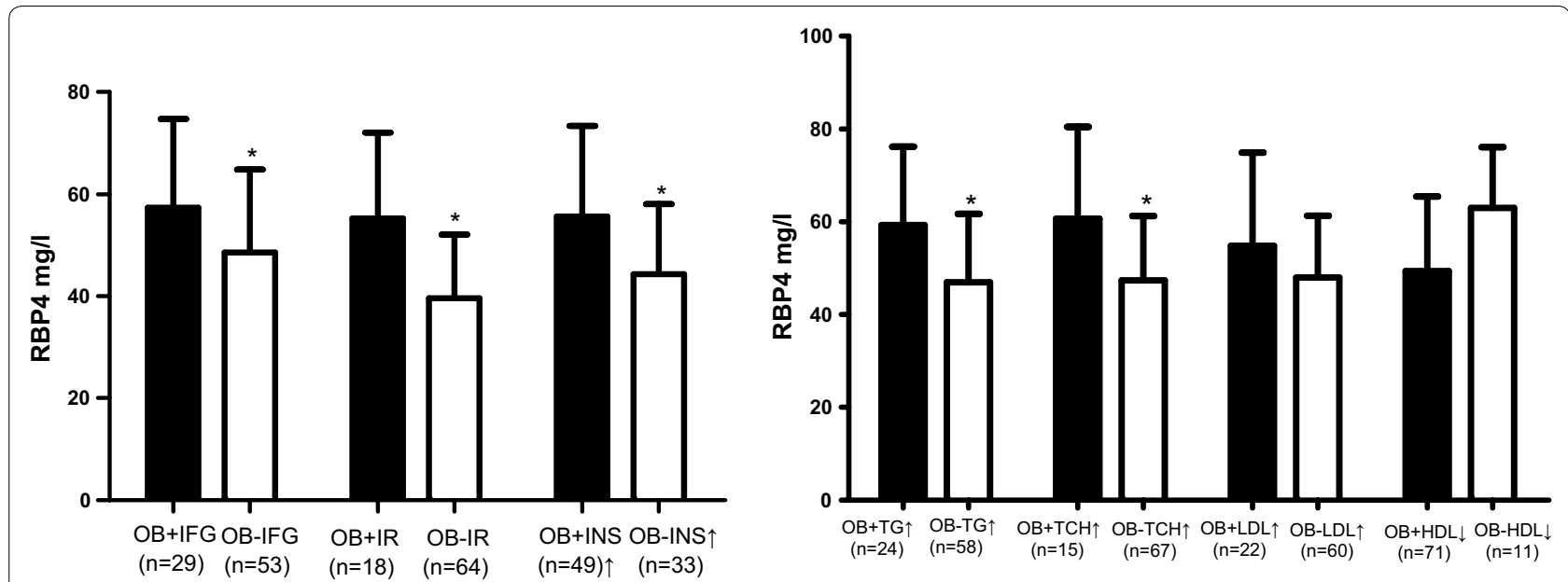

Fig. 2 RBP4 levels in all obesity with abnormal metabolism. RBP4 retinol-binding protein 4, OB obesity, IFG impaired fasting glucose, IR insulin resistance, INS insulin, TG triglyceride, TCH total cholesterol, LDL low-density lipoprotein cholesterol, HDL high-density lipoprotein cholesterol; ${ }^{*} P<0.05$

vs. $63.00 \pm 13.11 \mathrm{mg} / \mathrm{L}, P=0.164)$. All the data were presented in Fig. 2.

\section{Improved metabolism and decreased serum RBP4 levels after surgery}

Weight, BMI, WC, HC and, TG were significantly decreased in males and females at 3, 6 months after surgery (all $P<0.05$ ). TG at 3 and 6 months, UA at 6 months, SOD at 3 months after surgery were significantly decreased and HDL-C at 3, 6 months after surgery were significantly increased in females (all $P<0.05)$. SOD and HDL-C were significantly increased at 6 months after surgery in males (all $P<0.05$ ). All the results were showed in Table 2. LSG led to significantly decreased fasting glucose, FINS, and FCP at 3, 6 months after surgery (all $P<0.05$ ) as shown in Fig. 3. HOMA-IR at 3, 6 months in both genders, HOMA- $\beta$ at 3 months in females and at 6 months in males were significantly decreased after surgery (all $P<0.05)$ as presented in Fig. 4. Additionally, RBP4 levels were significantly decreased in all subjects after surgery with a significant difference (all $P=0.002$ ). RBP4 levels were significantly decreased from $43.50 \pm 12.11$ to $31.6 \pm 4.74 \mathrm{mg} / \mathrm{L}$ at 3 months, and to $28.83 \pm 13.74 \mathrm{mg} / \mathrm{L}$ at 6 months after surgery in males $(P=0.020$ and $P=0.017)$. RBP4 levels were significantly decreased from $43.07 \pm 15.48$ to $34.79 \pm 11.76 \mathrm{mg} / \mathrm{L}$ at 3 months, and to $32.00 \pm 11.94 \mathrm{mg} / \mathrm{L}$ at 6 months after surgery in females $(P=0.037$ and $P=0.027)$. It need be mentioned that RBP4 levels were slightly decreased from 3 months to 6 months after surgery without statistic difference in females, males and all subjects with obesity (all $P>0.05$ ). All these results were showed in
Fig. 5. RBP4 levels decreased by $16.7 \%$ and $19.6 \%$ in all obesity, $34.1 \%$ and $30.8 \%$ in males, $9.2 \%$ and $18.9 \%$ in females at 3 and 6 months after surgery respectively.

\section{Change in RBP4 levels associated with a change in metabolic markers after surgery}

In males, the change in serum RBP4 levels were significantly associated with a change in FINS, FCP, HOMAIR and HOMA- $\beta$ at 6 months and were associated with a change in TSH at 3 months after surgery (all $P<0.05$ ). In females, the change in serum RBP4 levels were significantly related to change in FINS, FCP, HOMA-, HOMA- $\beta$ and $\mathrm{TCH}$ at 3 months after surgery (all $P<0.05)$. The change in serum RBP4 levels were not significantly associated with the change in lipid profile while were significantly associated with FCP at 6 months in all obesity (all $P>0.05$ ). All results are presented in Table 3 .

\section{Discussion}

As a metabolic risk factor in obesity, RBP4 has been reported to be associated with insulin resistance and adipose accumulation. RBP4 levels are elevated in obesity and are positively associated with BMI and WHR [22-27]. In our study, RBP4 levels were also significantly higher in obese patients than healthy controls with normal BMI and RBP4 levels were also significantly associated with BMI in obesity. Additionally, RBP4 levels may decrease after weight loss. A study proved that RBP4 levels were reduced 6 months after gastric banding in morbidly obese subjects [14]. Decreased RBP4 is associated with changes in BMI, HOMA-IR and TCH (all $P<0.05$ ) [14]. Another study compared the SG to roux-en-y 


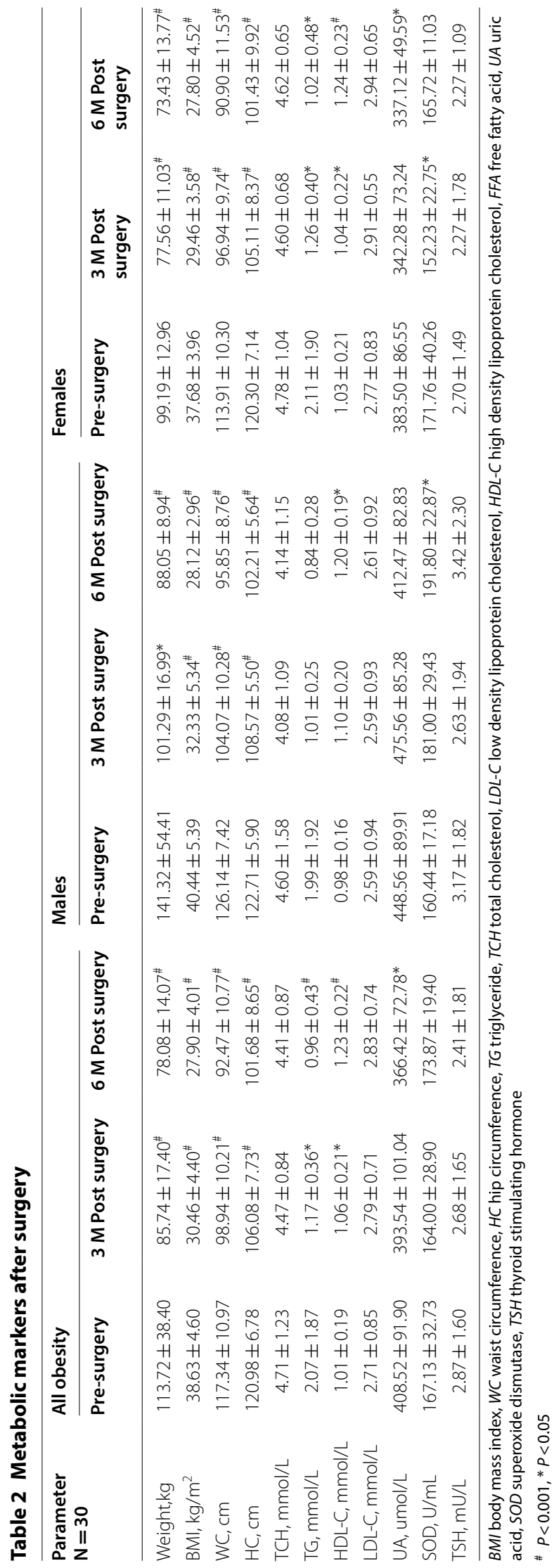



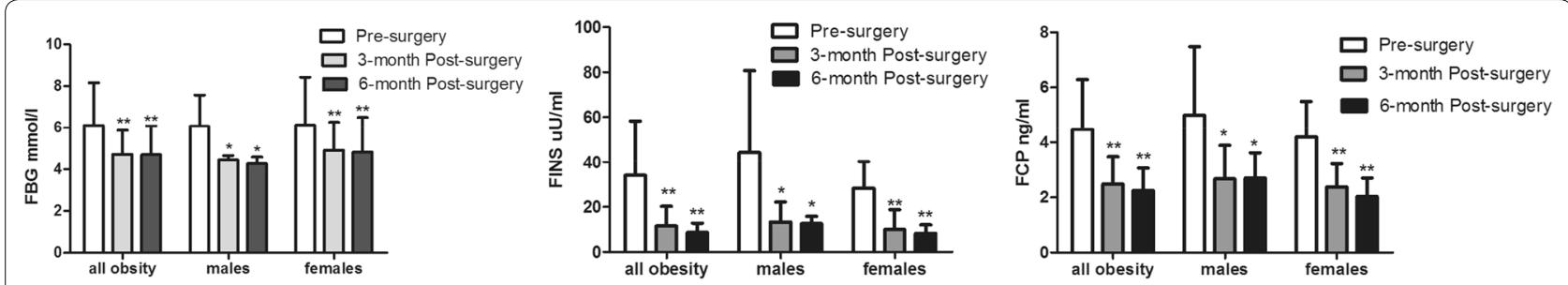

Fig. 3 Change in glucose metabolism. FBG fasting blood glucose, FINS fasting insulin, FCP fasting C-peptide; ${ }^{*} P<0.05$; ${ }^{* *} P<0.01$

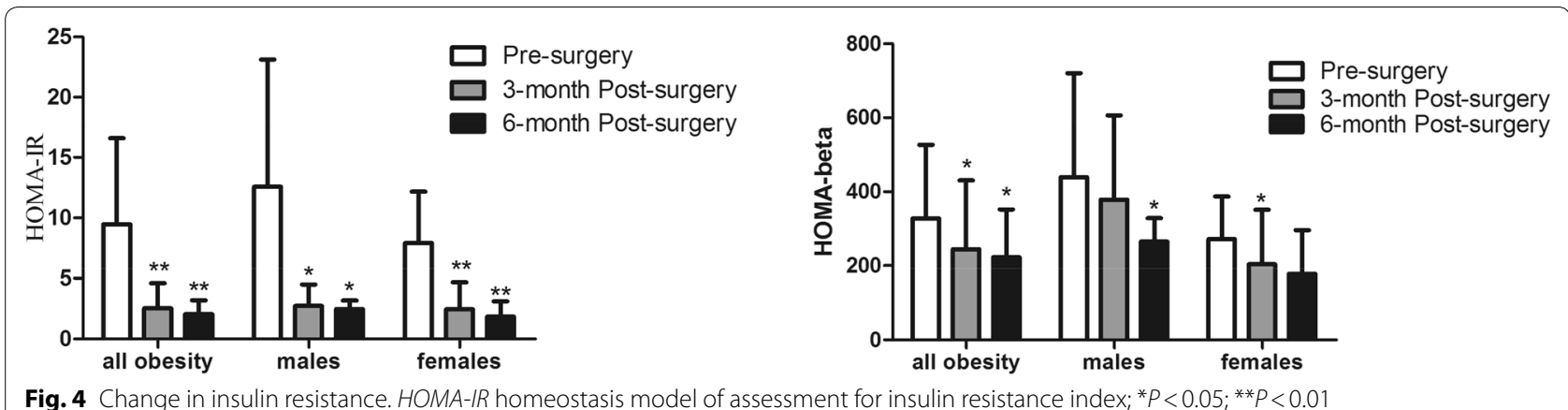

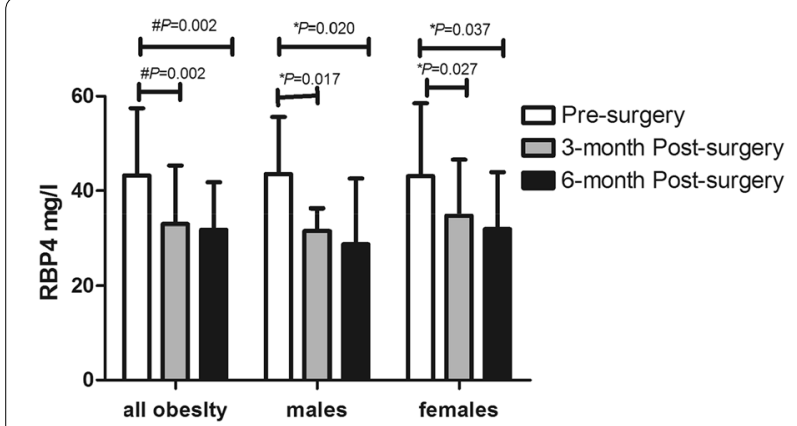

Fig. 5 Change in RBP4 levels. RBP4 retinol-binding protein 4; ${ }^{*} P<0.05 ; " P<0.01$

gastric bypass(GBP) in subjects with diabetes, the results showed that RBP4 was significantly decreased as early as 3 days after GBP [28]. By taking these facts into consideration, in this study, we have investigated the relationship between RBP4 and the other metabolic markers and the change of its levels after LSG. We demonstrated a marked decrease in serum RBP4 levels at 3 and 6 months after LSG. To our knowledge, this study is the first study to assess the change in RBP4 serum levels after LSG.

RBP4 was mostly secreted by the human liver and adipose tissue as an adipokine [8]. RBP4 contributes to the pathogenesis of type 2 diabetes. A study by Kahn BB has first documented the importance of RBP4 in insulin resistance [10]. Adipose-specific GLUT4 knockout [adipose-Glut $4(-/-)]$ mice show insulin resistance is related to increased RBP4 expression [10]. Additionally, the overexpression of RBP4 or injection of recombinant RBP4 in wild-type mice leads to the development of insulin resistance [10]. In this study, RBP4 levels were significantly and positively associated with BG0, BG30, BG120, BG180, INS0, CP0, HOMA-IR and HGB in females with obesity, and also significantly and positively associated with HOMA-IR and negatively with Matsuda index in males with obesity. Additionally, RBP4 levels of the patients with IFG, insulin resistance or hyperinsulinemia were significantly higher than the patients without IFG, insulin resistance or hyperinsulinemia. These results are consistent with previous studies that show RBP4 is significantly related to glucose metabolism in the human [10].

In addition to the influence of RBP4 on glucose metabolism, it also has a specific role in lipid metabolism. A previous study proved that elevated serum RBP4 is associated with increased serum TG levels and decreased HDL-C levels [27]. In this similar pattern, our study results show RBP4 levels were significantly and positively associated with TCH and TG in females with obesity but not in males. Additionally, RBP4 levels of patients with hypertriglyceridemia or hypercholesterolemia were significantly higher than patients with normal TG or TCH in females. Therefore, we can conclude that RBP4 interference with lipid metabolism is gender-dependent.

As a novel adipokine secreted by adipocyte, RBP4 is significantly higher in obese subjects than adults with normal weight $[29,30]$. RBP4 levels are also associated with oxidative stress and inflammatory markers 
Table 3 Change in RBP4 levels and metabolic markers

\begin{tabular}{|c|c|c|c|c|c|c|}
\hline \multirow[t]{2}{*}{ Parameter $(\mathrm{N}=30)$} & \multicolumn{2}{|c|}{ All obesity } & \multicolumn{2}{|l|}{ Males } & \multicolumn{2}{|l|}{ Females } \\
\hline & $r$ & $P$ & $\mathbf{r}$ & $P$ & $\mathbf{r}$ & $P$ \\
\hline 3M-del weight & 0.388 & 0.091 & 0.371 & 0.468 & 0.315 & 0.273 \\
\hline 6M-del weight & 0.199 & 0.495 & -0.359 & 0.553 & 0.326 & 0.391 \\
\hline 3M-del BMI & 0.208 & 0.379 & -0.143 & 0.787 & 0.185 & 0.527 \\
\hline 6M-del BMI & 0.093 & 0.752 & -0.667 & 0.219 & 0.310 & 0.417 \\
\hline 3M-del WC & -0.006 & 0.983 & 0.500 & 0.667 & -0.205 & 0.502 \\
\hline 6M-del WC & -0.322 & 0.262 & -0.308 & 0.614 & -0.444 & 0.232 \\
\hline 3M-del HC & -0.030 & 0.914 & -0.500 & 0.667 & -0.199 & 0.515 \\
\hline 6M-del HC & -0.344 & 0.228 & -0.564 & 0.332 & -0.206 & 0.595 \\
\hline 3M-del TCH & 0.169 & 0.477 & -0.200 & 0.704 & 0.537 & 0.048 \\
\hline $6 \mathrm{M}$-del TCH & 0.294 & 0.330 & -0.667 & 0.219 & 0.502 & 0.168 \\
\hline 3M-del TG & 0.122 & 0.609 & -0.257 & 0.623 & 0.295 & 0.306 \\
\hline 6M-del TG & 0.184 & 0.530 & 0.103 & 0.870 & 0.261 & 0.498 \\
\hline 3M-del HDL-C & 0.008 & 0.972 & 0.314 & 0.544 & 0.180 & 0.539 \\
\hline 6M-del HDL-C & -0.075 & 0.798 & -0.103 & 0.870 & -0.192 & 0.620 \\
\hline 3M-del LDL-C & -0.061 & 0.798 & -0.371 & 0.468 & 0.022 & 0.940 \\
\hline 6M-del LDL-C & 0.155 & 0.597 & -0.154 & 0.805 & 0.226 & 0.559 \\
\hline 3M-del FBG & 0.046 & 0.850 & 0.000 & 1.000 & 0.152 & 0.605 \\
\hline 6M-del FBG & 0.062 & 0.833 & -0.103 & 0.870 & 0.308 & 0.420 \\
\hline 3M-del FINS & 0.377 & 0.101 & -0.371 & 0.468 & 0.673 & 0.008 \\
\hline 6M-del FINS & 0.135 & 0.646 & -0.975 & 0.005 & 0.586 & 0.097 \\
\hline 3M-del FCP & 0.368 & 0.110 & -0.371 & 0.468 & 0.642 & 0.013 \\
\hline 6M-del FCP & 0.498 & 0.029 & -0.975 & 0.005 & 0.510 & 0.160 \\
\hline 3M-del HOMA-IR & 0.394 & 0.096 & -0.800 & 0.104 & 0.673 & 0.008 \\
\hline 6M-del HOMA-IR & 0.084 & 0.775 & -0.975 & 0.005 & 0.586 & 0.097 \\
\hline 3M-del HOMA- $\beta$ & 0.278 & 0.248 & 0.100 & 0.873 & 0.649 & 0.012 \\
\hline 6M-del HOMA- $\beta$ & 0.124 & 0.673 & -0.975 & 0.005 & 0.653 & 0.057 \\
\hline 3M-del TSH & 0.242 & 0.303 & -0.841 & 0.036 & -0.240 & 0.568 \\
\hline 6M-del TSH & -0.326 & 0.276 & -0.667 & 0.219 & 0.506 & 0.065 \\
\hline
\end{tabular}

$B M I$ body mass index, WC waist circumference, $H C$ hip circumference, FINS fasting insulin, FCP fasting $C$ peptide, HOMA-IR homeostasis model of assessment for insulin resistance index, $T G$ triglyceride, $T C H$ total cholesterol, $L D L-C$ low density lipoprotein cholesterol, $H D L-C$ high density lipoprotein cholesterol, $T S H$ thyroid stimulating hormone

$[13,31]$. There exists a positive association of RBP4 levels with oxidative stress markers such as SOD in males and females with obesity in this study. An interesting study demonstrates that plasma RBP4 levels are significantly associated with UA in the Chinese population [32]. In conclusion, RBP4 levels were found significant with serum UA levels in females with obesity.

TSH levels present a positive association with BMI and are increased in obese patients when compared to the control group with normal weight [33]. Obese patients with the complication of mild thyroid hormone deficiency exert more serious metabolic disturbance [34]. However, few studies involved studying the association of RBP4 levels with thyroid function in obesity. A previous study showed that RBP4 levels were positively associated with TSH in postmenopausal women [35]. RBP4 levels are higher in patients with clinical hypothyroidism than controls [36]. In this study, RBP4 levels were significantly and positively associated with TSH in obesity and the change in serum RBP4 levels were associated with change in TSH in 3rd month after LSG in males. Hence, we suggest that RBP4 may play a role in thyroid dysfunction in obesity.

Metabolic surgery is more and more popular worldwide for reducing body weight and improving metabolism. Insulin resistance is significantly improved earlier than weight loss after surgery [37]. In our study, body weight was significantly reduced and the metabolism was significantly improved at 3, 6 months after LSG. Glucose metabolism improved especially accompanied by decreased fasting glucose, FINS, FCP, HOMA-IR and HOMA- $\beta$ after surgery. However, the mechanism by which bariatric surgery improves glucose metabolism is unclear. Change of hormone secretion in the 
gastrointestinal tract may be one of those mechanisms $[38,39]$. RBP4 plays an important role in insulin resistance, and the improved glucose metabolism after LSG may be related to RBP4. A previous study illustrated the changes in RBP4 levels after gastric banding in morbidly obese subjects [14]. Another study also confirmed the change in RBP4 levels after GBP as early as 3 days [28]. While, they did not found change in RBP4 levels at 3 days after SG [28]. Therefore, we investigated the change in RBP4 levels after LSG with follow up time of 6 months. The results of our study showed that RBP4 levels were significantly decreased at 3, 6 months after surgery in males and females. Therefore, there exists change in RBP4 levels with long term after SG. RBP4 levels were closely associated with insulin resistance. Additionally, we found that the change in serum RBP4 levels were associated with change in FINS, FCP, HOMA-IR and HOMA- $\beta$ at 6 th month after LSG in males, and the change in serum RBP4 levels were related to change in FINS, FCP, HOMA-IR, and HOMA- $\beta$ at 3rd month after LSG in females. Therefore, we assume that decreased RBP4 levels may contribute to improved glucose metabolism after LSG.

There also some limitations to our study. The sample size is relatively smaller, and the follow-up time is relatively short. We will further expand the sample size and extend the follow-up time to observe the change in RBP4 for the long-term.

\section{Conclusion}

Overall, we relate the association between RBP4 with glucose metabolism, oxidative stress and thyroid function in patients of Chinese ethnicity. After the LSG surgery, the patients have shown improved glucose metabolism and decreased RBP4 levels in the 3rd and 6th months. Our study also suggests, decreased RBP4 levels may partly account for the improved glucose metabolism in obese patients after LSG. Future in-depth analyses on this area could project LSG as the most reliable treatment method for obesity and RBP4 as a trustable biomarker.

\section{Abbreviations \\ RBP4: serum retinol-binding protein 4; LSG: laparoscopic sleeve gastrectomy UA: uric acid; SOD: superoxide dismutase; FT3: free triiodothyronine; FT4: free thyroxin; TSH: thyrotropin; BMI: body mass index; FINS: fasting inulin; FCP: fasting C-peptide; HOMA-IR: homeostasis model of assessment for insulin resistance index; IFG: impaired fasting glucose.}

\section{Acknowledgements}

Not applicable.

\section{Author's contributions}

XW identified the concept, design the study and wrote the manuscript. YH and JG were involved in the analysis of data. HS was involved in editing the manuscript. MJ was involved in polishing the language. QS organized the paper and approved the final version. All author read and approved the final manuscript.

\section{Funding}

This research was supported by the National Natural Science Foundation of China (NSFC 81900781)

\section{Availability of data and materials}

Data are all contained within the paper.

\section{Ethics approval and consent to participate}

All procedures were in accordance with the ethical standards of the Ethical Committee of Shanghai Tenth People's Hospital. Informed consent was obtained from all subjects.

\section{Consent for publication}

Not applicable.

\section{Competing interests}

The authors declare that they have no competing interests.

\section{Author details}

${ }^{1}$ Department of Endocrinology and Metabolism, Shanghai Tenth People's Hospital, Tongji University, School of Medicine, Shanghai, China. ${ }^{2}$ National Metabolic Management Center, 10th Hospital, Shanghai 200072, China.

Received: 19 September 2019 Accepted: 20 December 2019 Published online: 14 January 2020

\section{References}

1. Wilson PW, D'Agostino RB, Sullivan L, Parise H, Kannel WB. Overweight and obesity as determinants of cardiovascular risk: the Framingham experience. Arch Intern Med. 2002;162(16):1867-72.

2. Li TY, Rana JS, Manson JE, Willett WC, Stampfer MJ, Colditz GA, Rexrode KM, Hu FB. Obesity as compared with physical activity in predicting risk of coronary heart disease in women. Circulation. 2006;113(4):499-506.

3. Riobo Servan P. Obesity and diabetes. Nutr Hosp. 2013;28(Suppl 5):138-43.

4. Shoar S, Saber AA. Long-term and midterm outcomes of laparoscopic sleeve gastrectomy versus Roux-en-Y gastric bypass: a systematic review and meta-analysis of comparative studies. Surg Obes Related Dis. 2017;13(2):170-80

5. Magouliotis DE, Tasiopoulou VS, Svokos AA, Svokos KA, Sioka E, Zacharoulis D. Roux-En-Y gastric bypass versus sleeve gastrectomy as revisional procedure after adjustable gastric band: a systematic review and meta-analysis. Obes Surg. 2017;27(5):1365-73.

6. Switzer NJ, Prasad S, Debru E, Church N, Mitchell P, Gill RS. Sleeve gastrectomy and type 2 diabetes mellitus: a systematic review of longterm outcomes. Obes Surg. 2016;26(7):1616-21.

7. Wang Y, Yi XY, Gong LL, Li QF, Zhang J, Wang ZH. The effectiveness and safety of laparoscopic sleeve gastrectomy with different sizes of bougie calibration: a systematic review and meta-analysis. Int J Surg. 2017:49:32-8.

8. Kotnik P, Fischer-Posovszky P, Wabitsch M. RBP4: a controversial adipokine. Eur J Endocrinol Eur Fed Endocr Soc. 2011;165(5):703-11.

9. Majerczyk M, Olszanecka-Glinianowicz M, Puzianowska-Kuznicka M, Chudek J. Retinol-binding protein 4 (RBP4) as the causative factor and marker of vascular injury related to insulin resistance. Postepy higieny i medycyny doswiadczalnej. 2016;70:1267-75.

10. Yang Q, Graham TE, Mody N, Preitner F, Peroni OD, Zabolotny JM, Kotani K, Quadro L, Kahn BB. Serum retinol binding protein 4 contributes to insulin resistance in obesity and type 2 diabetes. Nature. 2005;436(7049):356-62.

11. Cheng J, Li Y, Wu G, Zheng J, Lu H, Shi X, Yang G. Ectopic expression of RBP4 impairs the insulin pathway and inguinal fat deposition in mice. J Physiol Biochem. 2014;70(2):479-86.

12. Jia W, Wu H, Bao Y, Wang C, Lu J, Zhu J, Xiang K. Association of serum retinol-binding protein 4 and visceral adiposity in Chinese 
subjects with and without type 2 diabetes. J Clin Endocrinol Metab. 2007;92(8):3224-9.

13. Liu Y, Wang D, Li D, Sun R, Xia M. Associations of retinol-binding protein 4 with oxidative stress, inflammatory markers, and metabolic syndrome in a middle-aged and elderly Chinese population. Diabetol Metab Syndr. 2014;6(1):25.

14. Haider DG, Schindler K, Prager G, Bohdjalian A, Luger A, Wolzt M, Ludvik $B$. Serum retinol-binding protein 4 is reduced after weight loss in morbidly obese subjects. J Clin Endocrinol Metab. 2007:92(3):1168-71.

15. Silvestre V, Ruano M, García-Lescún MC, Aguirregoicoa E, Criado L, Rodríguez A, Marco A, García-Blanch G. Morbid obesity, non-alcoholic fatty liver disease, metabolic syndrome and bariatric surgery. Nutr Hosp. 2007:22(5):602-6.

16. Tschoner A, Sturm W, Engl J, Kaser S, Laimer M, Laimer E, Weiss $H$, Patsch JR, Ebenbichler CF. Retinol-binding protein 4, visceral fat, and the metabolic syndrome: effects of weight loss. Obesity. 2008;16(11):2439-44

17. Abdul-Ghani MA, Tripathy D, DeFronzo RA. Contributions of beta-cell dysfunction and insulin resistance to the pathogenesis of impaired glucose tolerance and impaired fasting glucose. Diabetes Care. 2006;29(5):1130-9.

18. Matthews DR, Hosker JP, Rudenski AS, Naylor BA, Treacher DF, Turne RC. Homeostasis model assessment: insulin resistance and beta-cel function from fasting plasma glucose and insulin concentrations in man. Diabetologia. 1985;28(7):412-9.

19. Henríquez S, Jara N, Bunout D, Hirsch S, de la Maza MP, Leiva L, Barrera G. Variability of formulas to assess insulin sensitivity and their association with the Matsuda index. Nutr Hosp. 2013;28(5):1594-8.

20. Genuth S, Alberti KG, Bennett P, Buse J, Defronzo R, Kahn R, Kitzmiller J, Knowler WC, Lebovitz H, Lernmark A, et al. Follow-up report on the diagnosis of diabetes mellitus. Diabetes Care. 2003;26(11):3160-7.

21. Back Giuliano Ide C, Caramelli B, Pellanda L, Duncan B. I Guidelines of prevention of atherosclerosis in childhood and adolescence. Arquivos brasileiros de cardiologia. 2005;85(Suppl 6):4-36.

22. Lee DC, Lee JW, Im JA. Association of serum retinol binding protein 4 and insulin resistance in apparently healthy adolescents. Metab Clin Exp. 2007;56(3):327-31.

23. Aeberli I, Biebinger R, Lehmann R, L'allemand D, Spinas GA, Zimmermann MB. Serum retinol-binding protein 4 concentration and its ratio to serum retinol are associated with obesity and metabolic syndrome components in children. J Clin Endocrinol Metab. 2007;92(11):4359-65.

24. Reinehr T, Stoffel-Wagner B, Roth CL. Retinol-binding protein 4 and its relation to insulin resistance in obese children before and after weight loss. J Clin Endocrinol Metab. 2008;93(6):2287-93.

25. Lu HY, Li XF, Mu PW, Jiang W, Zeng LY. Depot-specific expression of retinol-binding protein 4 in human adipose tissue and their relationship with obesity and insulin resistance. Zhonghua yi xue za zhi. 2010;90(48):3395-8.

26. Friebe D, Neef M, Erbs S, Dittrich K, Kratzsch J, Kovacs P, Blüher M, Kiess W, Körner A. Retinol binding protein 4 (RBP4) is primarily associated with adipose tissue mass in children. Int J Pediatr Obes. 2011;6(2-2):e345-52.

27. Graham TE, Yang Q, Blüher M, Hammarstedt A, Ciaraldi TP, Henry RR, Wason CJ, Oberbach A, Jansson PA, Smith U, et al. Retinol-binding protein 4 and insulin resistance in lean, obese, and diabetic subjects. N Engl J Med. 2006;354(24):2552-63.

28. Jüllig M, Yip S, Xu A, Smith G, Middleditch M, Booth M, Babor R, Beban G, Murphy R. Lower fetuin-A, retinol binding protein 4 and several metabolites after gastric bypass compared to sleeve gastrectomy in patients with type 2 diabetes. PLoS ONE. 2014;9(5):e96489.

29. Kim IK, Lee HJ, Kang JH, Song J. Relationship of serum retinol-binding protein 4 with weight status and lipid profile among Korean children and adults. Eur J Clin Nutr. 2011;65(2):226-33.

30. Comucci EB, Vasques AC, Geloneze B, Calixto AR, Pareja JC, Tambascia MA. Serum levels of retinol binding protein 4 in women with different levels of adiposity and glucose tolerance. Arquivos brasileiros de endocrinologia e metabologia. 2014;58(7):709-14.

31. Zabetian-Targhi F, Mahmoudi MJ, Rezaei N, Mahmoudi M. Retinol binding protein 4 in relation to diet, inflammation, immunity, and cardiovascular diseases. Adv Nutr. 2015:6(6):748-62.

32. Li F, Yang T, Zhao Z, Xia K. Plasma level of RBP4 in patients with coronary heart disease and the effect of hyperinsulinemia. Zhong nan da xue xue bao Yi xue ban = J Central South Univ Med Sci. 2012;37(11):1177-82.

33. Portmann L, Giusti V. Obesity and hypothyroidism: myth or reality? Revue medicale suisse. 2007;3(105):859-62.

34. Wang X, Liu H, Chen J, Huang Y, Li L, Rampersad S, Qu S. Metabolic characteristics in obese patients complicated by mild thyroid hormone deficiency. Horm Metab Res. 2016:48(5):331-7.

35. Güdücü N, Görmüş U, Kavak ZN, İş̧i H, Yiğiter AB, Dünder İ. Retinolbinding protein 4 is elevated and is associated with free testosterone and TSH in postmenopausal women. J Endocrinol Invest. 2013;36(10):831-4.

36. Kokkinos S, Papazoglou D, Zisimopoulos A, Papanas N. Retinol binding protein-4 and adiponectin levels in thyroid overt and subclinical dysfunction. Exp Clin Endocrinol Diabetes. 2016;124(2):87-92.

37. Kokkinos S, Papazoglou D, Zisimopoulos A, Papanas N, Tiaka E, Antonoglou C, Maltezos E. Changes in oxidative stress and insulin resistance in morbidly obese patients after bariatric surgery. Obes Surg. 2010;20(3):363-8.

38. Laferrere B. Bariatric surgery and obesity: influence on the incretins. Int J Obes Suppl. 2016:6(Suppl 1):S32-6.

39. Smith EP, Polanco G, Yaqub A, Salehi M. Altered glucose metabolism after bariatric surgery: what's GLP-1 got to do with it? Metab Clin Exp. 2017:83:159-66.

\section{Publisher's Note}

Springer Nature remains neutral with regard to jurisdictional claims in published maps and institutional affiliations.
Ready to submit your research? Choose BMC and benefit from:

- fast, convenient online submission

- thorough peer review by experienced researchers in your field

- rapid publication on acceptance

- support for research data, including large and complex data types

- gold Open Access which fosters wider collaboration and increased citations

- maximum visibility for your research: over $100 \mathrm{M}$ website views per year

At BMC, research is always in progress.

Learn more biomedcentral.com/submissions 